\title{
The Metabolism of Niacytin in the Rat
}

\author{
TRIGONELLINE AS A MAJOR METABOLITE OF NIACYTIN IN THE URINE
}

\author{
BY J. B. MASON AND E. KODICEK \\ Dunn Nutritional Laboratory, University of Cambridge and Medical Research Council, \\ Cambridge CB4 $1 X J, U . K$.
}

(Received 30 June 1970)

\begin{abstract}
1. To investigate the fate of orally administered niacytin, urine and faeces of rats given single niacytin doses were examined for nicotinic acid derivatives methylated on the pyridine nitrogen atom, determined as trigonelline. 2. Methods were devised for the extraction of trigonelline from urine and faeces and for its differentiation from $N^{\prime}$-methylnicotinamide. 3. A prolonged elevation of the excretion of trigonelline in the urine of rats dosed with niacytin was detected colorimetrically, in contrast with the urinary excretion in control groups given free nicotinic acid or hydrolysed niacytin. The total conversion of the nicotinoyl moiety of niacytin into trigonelline was $30-40 \%$. 4. The identity of this metabolite as trigonelline was established by t.l.c., by its u.v. spectrum and by g.l.c. after conversion into methyl nicotinate. 5 . The excretion of Ehrlich-positive substances was also increased in urine after administration of niacytin, the increase being approximately parallel to the trigonelline excretion. 6. No increase in the excretion of trigonelline in faeces was found after administration of niacytin. 7. These results suggest a metabolic pathway for niacytin in the rat involving methylation of the pyridine nitrogen without prior release of free nicotinic acid. This hypothesis explains the absence of biological activity of niacytin. An endogenous source of urinary trigonelline was also demonstrated.
\end{abstract}

Niacytin, the unavailable form of nicotinic acid in cereals, was shown not to be metabolized via a direct turnover of nicotinic acid in the rat (Mason \& Kodicek, 1970). Further, after administration of niacytin little or none of the dose was detected in faeces or urine as tertiary nicotinoyl derivatives, indicating that the substance was not simply excreted unchanged. Faeces and urine were therefore examined for possible metabolites of niacytin. Methylation of the pyridine nitrogen atom was considered as a possible mode of metabolism of the nicotinic acid moiety of niacytin, either by gut bacteria or by the animal itself after absorption of niacytin or of a niacytin fragment containing bound nicotinic acid. The trigonelline $\left(N^{\prime}\right.$-methylnicotinic acid) content of the faeces and urine was therefore investigated. Since niacytin has been shown to contain an aromatic amine (Kodicek \& Wilson, 1960) having a positive reaction with Ehrlich's reagent, the excretion of Ehrlich-positive substances was also studied.

Preliminary reports of the results (Mason \& Kodicek, 1968 $a$ ) and of the methods for trigonelline determination (Mason \& Kodicek, 1968b) have been published.

\section{MATERIALS AND METHODS}

Animals and diet. The animals and diet were similar to those described in the preceding paper (Mason \& Kodicek, 1970). The groups of four rats were dosed as follows, each dose containing $\mathrm{lmg}$ of free or bound nicotinic acid: group 1, undosed control; group 2, free nicotinic acid; group 3, niacytin; groups $4 a$ and $4 b$, hydrolysed niacytin. The preliminary experiments described below (see the Results section) refer to urine and faeces samples obtained from rats (undosed and dosed with niacytin) in the experiments described by Mason \& Kodicek (1970).

Doses. The doses were administered by stomach tube. Animals in group 2 each received $0.5 \mathrm{ml}$ of an aqueous solution containing $2.0 \mathrm{mg}$ of nicotinic acid $/ \mathrm{ml}$. Animals in group 3 each received $0.5 \mathrm{ml}$ of a solution containing $74.0 \mathrm{mg}$ of niacytin $/ \mathrm{ml}$, equivalent to $2.0 \mathrm{mg}$ of bound nicotinic acid/ml. Niacytin was prepared as described by Mason \& Kodicek (1970). Animals in groups $4 a$ and $4 b$ each received $0.5 \mathrm{ml}$ of a hydrolysed niacytin solution in which the nicotinic acid present was entirely as the free acid; niacytin $(185 \mathrm{mg} / \mathrm{ml})$ was hydrolysed in $5 \mathrm{M}-\mathrm{NaOH}$ at $100^{\circ} \mathrm{C}$ for $15 \mathrm{~min}$, neutralized and made up to final concentration of $74.0 \mathrm{mg} / \mathrm{ml}$. The free nicotinic acid content of this solution was $2.0 \mathrm{mg} / \mathrm{ml}$.

Collection of urine and faeces. Urine was collected over chloroform and stored at $-15^{\circ} \mathrm{C}$. The urine from each 
group of rats was filtered and pooled daily and made up to $60 \mathrm{ml}$ with water. Faeces were pooled daily for each group as described by Mason \& Kodicek (1970).

Determination of trigonelline. Faeces were extracted with $0.5 \mathrm{M}-\mathrm{NaOH}$ (approx. $10 \mathrm{ml} / 0.3 \mathrm{~g}$ ) at $100^{\circ} \mathrm{C}$ for $20 \mathrm{~min}$, the $\mathrm{pH}$ was adjusted to 7.0 and the mixture was centrifuged at approx. $400 \mathrm{~g}$ for $20 \mathrm{~min}$. The volume was concentrated in vacuo to $12 \mathrm{ml}$ and the cloudy precipitate that formed was removed by centrifugation at approx. $6000 \mathrm{~g}$ for 30 min. A $10 \mathrm{ml}$ portion of the supernatant was applied to a column $(3.5 \mathrm{~cm} \times 40 \mathrm{~cm})$ of Sephadex G-10, set up with water. Trigonelline was eluted with water at $35-85 \mathrm{ml}$ after the void volume $(140-190 \mathrm{ml}$ after application). This fraction was concentrated to $15 \mathrm{ml}$ in vacuo and trigonelline was determined as described below.

Trigonelline was extracted from urine by column chromatography on Sephadex G-10 or by ion-exchange chromatography (this latter procedure removed $N^{\prime}$. methylnicotinamide). For the former method $10 \mathrm{ml}$ of urine was chromatographed on a column $(3.5 \mathrm{~cm} \times 40 \mathrm{~cm})$ of Sephadex G-10 with water, as for faeces, and the trigonelline fraction was similarly treated. The procedure using ion-exchange chromatography was as follows. Dowex 50W ( $\mathrm{H}^{+}$form) (Bio-Rad Laboratories, Berkeley, Calif., U.S.A.) was prepared as described by Wall (1953), and a portion of the resin was converted into the $\mathrm{Na}^{+}$form at $\mathrm{pH} 7.0$ by treatment with excess of $5 \mathrm{M}$ $\mathrm{NaCl}$ and then $50 \mathrm{~mm}$-sodium phosphate buffer, $\mathrm{pH}$ 7.0. Columns (each $1 \mathrm{~cm} \times 5 \mathrm{~cm}$ ), of each form were packed under $5 \mathrm{lb} / \mathrm{in}^{2} \mathrm{~N}_{2}$ pressure. The $\mathrm{H}^{+}$-form columns were washed with $100 \mathrm{ml}$ of $5 \mathrm{M}-\mathrm{HCl}$ and then $200 \mathrm{ml}$ of $50 \mathrm{~mm}$ $\mathrm{HCl}$ after each use; the $\mathrm{Na}^{+}$-form columns were washed with $100 \mathrm{ml}$ of $5 \mathrm{M}-\mathrm{NaCl}$ and then $200 \mathrm{ml}$ of $50 \mathrm{~mm}$-sodium phosphate buffer, pH 7.0, after each use. All operations were carried out under $1.5-2.0 \mathrm{lb} / \mathrm{in}^{2} \mathrm{~N}_{2}$ pressure. To $20 \mathrm{ml}$ of urine was added $2.2 \mathrm{ml}$ of $0.5 \mathrm{M}$-sodium phosphate buffer, pH 7.0, and the solution was passed through the $\mathrm{Na}^{+}$-form column. Then $20 \mathrm{ml}$ of $0.4 \mathrm{M}-\mathrm{Na}^{+}(0.1 \mathrm{M}$ in phosphate, pH 7.0, 0.3 $\mathrm{M}$ in $\mathrm{Cl}^{-}$) was passed through and pooled with the first fraction. Then $4.4 \mathrm{ml}$ of $5 \mathrm{M}-\mathrm{HCl}$ was added to this solution and it was passed through the $\mathrm{H}^{+}$-form column, followed by $25 \mathrm{ml}$ of $1.0 \mathrm{M}-\mathrm{HCl}$. The eluates were pooled and kept as fraction 1 . This was followed by $3 \mathrm{ml}$ and then $30 \mathrm{ml}$ of $3.0 \mathrm{M}-\mathrm{HCl}$, which were passed through the column, and the eluate was collected as fraction 2. $N^{\prime}$-Methylnicotinamide was retained on the $\mathrm{Na}^{+}$-form column; trigonelline was initially retained on the $\mathrm{H}^{+}$-form column and finally eluted with 3.0 M-HCl. Fraction 2, containing trigonelline, was evaporated to dryness in vacuo and the residue was dissolved in $15 \mathrm{ml}$ of water. The recovery of authentic trigonelline added to urine was found to be $84 \% \pm 7$ (s.r.m.). Fraction 1 was used for determination of Ehrlich-positive substances (see below).

When $10 \mathrm{ml}$ of urine was used the quantities of eluent

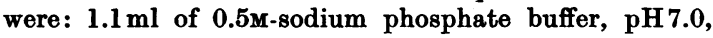
added initially to the urine; $25 \mathrm{ml}$ of $0.4 \mathrm{M}-\mathrm{Na}^{+}(0.1 \mathrm{M}$ in phosphate, $\mathrm{pH} 7.0,0.3 \mathrm{M}$ in $\left.\mathrm{Cl}^{-}\right) ; 4.0 \mathrm{ml}$ of $5 \mathrm{M}-\mathrm{HCl}$; and $25 \mathrm{ml}$ of $1.0 \mathrm{M}-\mathrm{HCl}$; other volumes were the same.

Trigonelline was determined in urine and faeces extracts by a modification of the method of Kodicek \& Wang (1941). The procedure was as follows. Conical flasks $50 \mathrm{ml}$ ) with ground glass necks were set up as follows: reagent blank, $4.0 \mathrm{ml}$ of water; external standard, $3.0 \mathrm{ml}$ of water $+1.0 \mathrm{ml}$ of trigonelline standard $(5 \mu \mathrm{g} / \mathrm{ml})$; unknown (two per sample), $3.0 \mathrm{ml}$ of extract $+1.0 \mathrm{ml}$ of water; internal standard (two per sample), $3.0 \mathrm{ml}$ of extract $+1.0 \mathrm{ml}$ of trigonelline standard $(5 \mu \mathrm{g} / \mathrm{ml})$. The extract should contain less than $2.5 \mu \mathrm{g}$ of trigonelline $/ \mathrm{ml}$. Authentic trigonelline hydrochloride was obtained from Aldrich Chemical Co. Inc., Milwaukee, Wis., U.S.A.

Any number of flasks (in practice up to 26) could be used for the determination at one time. The solutions were treated at $5 \mathrm{~min}$ or $10 \mathrm{~min}$ intervals as follows. To each flask were added $0.4 \mathrm{ml}$ of aq. $10 \%(\mathrm{w} / \mathrm{v}) \mathrm{BaCl}_{2}, 17 \mathrm{ml}$ of aq. $96 \%(v / v)$ ethanol and $4.0 \mathrm{ml}$ of aq. $50 \%(\mathrm{w} / \mathrm{v})$ $\mathrm{NaOH}$. The flask was flushed with $\mathrm{N}_{2}$ for 3 min by using a Drechsel top, which was then rapidly exchanged for the glass stopper smeared with glycerol and held in place with springs. The mixture was shaken at $70^{\circ} \mathrm{C}$ for $90 \mathrm{~min}$. The flask was then removed to a water bath at $25^{\circ} \mathrm{C}$, cooled for exactly $9 \mathrm{~min}$ and adjusted to $\mathrm{pH} 1-2$ with a predetermined volume of conc. $\mathrm{HCl}(4.6-4.8 \mathrm{ml}$; determined by a blank titration with 2,4-dinitrophenol indicator). After further cooling at $25^{\circ} \mathrm{C}$ for exactly $5 \mathrm{~min}$ the mixture was centrifuged for $3 \mathrm{~min}$ and two $10 \mathrm{ml}$ portions were removed to stoppered test tubes. Exactly 9 min after acidification $1 \mathrm{ml}$ of benzidine solution [ $1 \%(\mathrm{w} / \mathrm{v})$ benzidine (Hopkin and Williams Ltd., Chadwell Heath, Essex, U.K.) in $0.75 \mathrm{M}-\mathrm{HCl}-96 \%$ ethanol $(3: 1, v / v)]$ was added to one tube. To the other, $1 \mathrm{ml}$ of a blank reagent $[0.75 \mathrm{M}-\mathrm{HCl}-$ $96 \%$ ethanol $(3: 1, v / v)$ ] was added and the solutions were thoroughly mixed. They were kept at $25^{\circ} \mathrm{C}$ for at least $30 \mathrm{~min}$, and the $E_{510}$ values were then determined in $4 \mathrm{~cm} \times 1 \mathrm{~cm}$ glass cells. The response was linear up to a total of $15 \mu \mathrm{g}$ of trigonelline per flask. If this amount of trigonelline was exceeded the external standard value was used for calculation; otherwise the internal standard value was used.

The $E_{510}$ values were corrected for their blank values and also by subtraction of the reagent-blank reading. Contamination with acetaldehyde condensation products formed by oxidation of ethanol occurred if the flushing with $\mathrm{N}_{2}$ was inefficient or if impure reagents were used; these products reacted intensely with benzidine and interfered with the determination. The reagent blank was a check for this, and any unusually high readings were discarded. The coefficient of variation for internal standards was $11 \%$.

Thin-layer chromatography. The system ethanol-aq. 1 m-ammonium acetate, pH5 $(7: 3, v / v)$ (system I) was used for trigonelline and niacytin (Joshi \& Handler, 1962) and methanol-aq. ammonia solution (sp.gr. 0.88) $(3: 1, \mathrm{v} / \mathrm{v})$ (system II) (Eneroth \& Lindstedt, 1965), with $0.25 \mathrm{~mm}$ activated layers of silica gel $\mathrm{GF}_{254}$ (E. Merck A.-G., Darmstadt, Germany) for trigonelline. Compounds were detected against the fluorescent background under $254 \mathrm{~nm}$ illumination, with iodine vapour and with Ehrlich's reagent $[0.5 \%(w / v) p$-dimethylaminobenzaldehyde in aq. $96 \%(v / v)$ ethanol containing $1 \%$ of conc. $\mathrm{HCl}]$ for niacytin, which gave an intense orange-yellow reaction immediately in the cold.

Gas-liquid chromatography of trigonelline. Trigonelline was converted into methyl nicotinate for g.l.c. as follows. Urine was initially purified by the ion-exchange procedure described above, and the trigonelline fraction (fraction 2) was evaporated to dryness and redissolved in $5.0 \mathrm{ml}$ of aq. $50 \%(v / v)$ methanol. Two $2.4 \mathrm{ml}$ portions were taken, authentic trigonelline was added to one, the volumes were 
adjusted suitably and the samples were applied as $4 \mathrm{~cm}$ bands at the origin of $0.25 \mathrm{~mm}$ t.l.c. plates of silica gel $\mathbf{G F}_{254}$. The chromatograms were developed in system I or II, and the trigonelline band was identified under u.v. illumination by comparison with authentic trigonelline side-markers. The bands were scraped off and eluted with about $5 \mathrm{ml}$ of aq. $50 \%$ methanol into a $20 \mathrm{~cm} \times 0.8 \mathrm{~cm}$ tube. The eluate was evaporated to dryness under a stream of $\mathrm{N}_{2}$ at $50^{\circ} \mathrm{C}$ and the residue redissolved in $0.1 \mathrm{ml}$ of $0.5 \mathrm{M}$ HCl. The tube was sealed under $\mathrm{N}_{2}$ and heated in a fluidized sand bath at $275^{\circ} \mathrm{C}$ for $30 \mathrm{~min}$. The tube was opened, the solution again dried and the residue dissolved in $0.05 \mathrm{ml}$ of $1 \mathrm{M}-\mathrm{HCl}$ and $0.25 \mathrm{ml}$ of methanol. This solution was added dropwise to $2 \mathrm{ml}$ of diazomethane in ether, freshly prepared by the method of De Boer \& Backer (1954), and washed in with $0.3 \mathrm{ml}$ of methanol. The mixture was immediately evaporated to dryness under $\mathrm{N}_{2}$ and the residue was dissolved in $0.1 \mathrm{ml}$ of water. Portions $(5 \mu \mathrm{l})$ were taken for g.l.c. The yield of methyl nicotinate from trigonelline was low and variable ( $1-40 \%)$, owing to inefficiency of the demethylation step; the yield of methyl nicotinate from authentic nicotinic acid by treatment with diazomethane was consistently $80-90 \%$. Two g.l.c. columns were used. The first was a $1.2 \mathrm{~m}$ column of $10 \%$ Apiezon $L$ on silicone-treated Celite at $150^{\circ} \mathrm{C}$; the carrier gas was argon at a flow rate of $60 \mathrm{ml} / \mathrm{min}$. The retention time of methyl nicotinate was $2.7 \mathrm{~min}$ in this system. The second was a $1.8 \mathrm{~m}$ column of $4 \%$ Carbowax 400 on silicone-treated Celite at $100^{\circ} \mathrm{C}$; the carrier gas was argon at a flow rate of $30 \mathrm{ml} / \mathrm{min}$. The retention time of methyl nicotinate was approx. $2.7 \mathrm{~min}$ in this system. An F \& M Scientific (Hewlett-Packard) model 402 High Efficiency Gas Chromatograph, with a hydrogen flame detector, was used.

Determination of Ehrlich-positive substances in urine. Total Ehrlich-positive substances were determined in fraction 1 from the Dowex ion-exchange procedure (no reaction being found in other fractions) as follows. To $10 \mathrm{ml}$ of fraction 1 was added $1.0 \mathrm{ml}$ of $2.5 \%(w / v) p$ dimethylaminobenzaldehyde (Ehrlich's reagent) in aq. $96 \%(v / v)$ ethanol containing $1 \%$ of conc. HCl. After $10 \mathrm{~min}$ the $E_{430}$ value was measured in a $4 \mathrm{~cm} \times 1 \mathrm{~cm}$ glass cell against a reagent blank.

\section{RESULTS}

Excretion of N-methylated nicotinic acid derivatives in faeces. Faeces, extracted and digested with alkali and fractionated on Sephadex G-10, were assayed for trigonelline. No change in the trigonelline excretion in faeces was found, eliminating the possibility that the intestinal microflora was $N$. methylating the nicotinoyl moiety of niacytin.

Excretion of trigonelline in urine. Trigonelline was determined by the method of Kodicek \& Wang (1941) in whole urine obtained in preliminary experiments. The results indicated that there was an increase in trigonelline excretion after administration of niacytin, amounting to 60 and $100 \mu \mathrm{g} / \mathrm{rat}$ per day on the first and second days after dosing respectively. These findings were extended in another preliminary experiment in which trigonel-

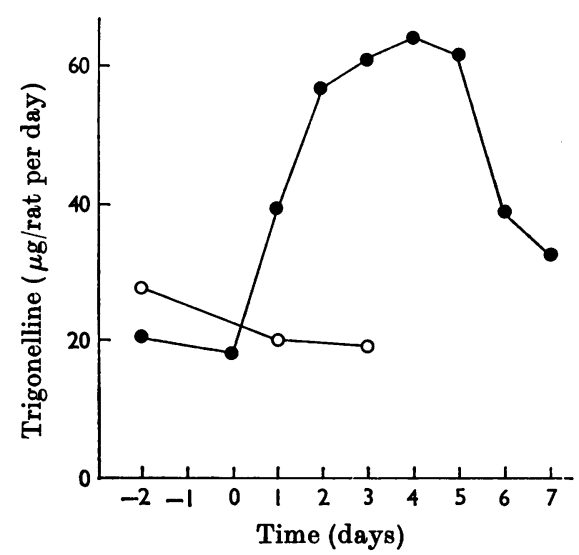

Fig. 1. Excretion of trigonelline in urine of rats dosed with niacytin containing $1 \mathrm{mg}$ of nicotinic acid on day $0(\bullet)$ and of undosed rats (O). Trigonelline was determined in urine, after fractionation on a column of Sephadex G-10, by the modified method described in the text.

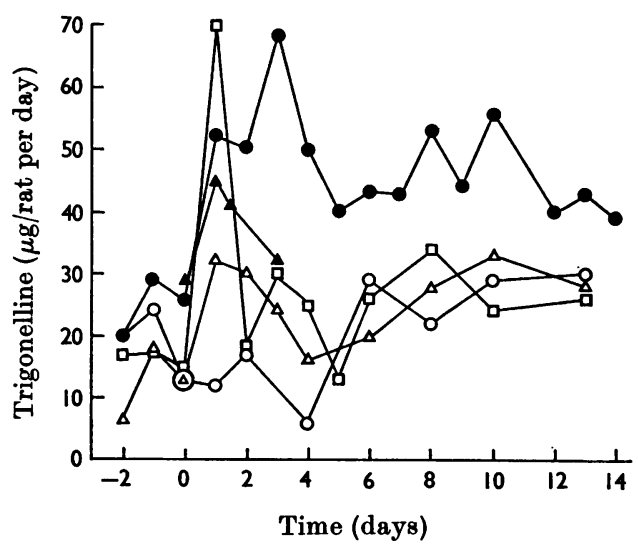

Fig. 2. Excretion of trigonelline in urine of rats given a single dose containing $1 \mathrm{mg}$ of free or bound nicotinic acid on day 0: $O$, undosed control (group 1); $\Delta$, nicotinic acid (group 2); ๑, niacytin (group 3); $\square$, hydrolysed niacytin (group $4 a) ; \Delta$, hydrolysed niacytin (group $4 b$ ). Trigonelline was determined in urine, after fractionation by ionexchange chromatography on Dowex 50W $\left(\mathrm{Na}^{+}\right.$form and $\mathrm{H}^{+}$form), by the modified method described in the text.

line was determined, after extraction by using Sephadex G-10, by the modified chemical procedure described above. An increase in trigonelline excretion was again noted (see Fig. 1).

In the main experiment control groups dosed with free nicotinic acid and with hydrolysed niacytin were included, and the more satisfactory ionexchange procedure for fractionation of urine was used; these results are shown in Fig. 2. Urine was 
collected for 14 days after dosing. For the niacytindosed animals in group 3 trigonelline was determined in each $24 \mathrm{~h}$ urine; for the other groups determinations were generally done on alternate $24 \mathrm{~h}$ urines. The variation between different days, particularly in the undosed control group (group 1), was largely due to technical difficulties in the collection of urine. The overall gradual increase in trigonelline excretion with time is probably not accountable for by the growth of the animals, again particularly in group 1; this has not been investigated further. The high excretion of trigonelline in the first day after dosing in group $4 a$ (hydrolysedniacytin-dosed) was less marked in the duplicate group $4 b$. The total recoveries of trigonelline in groups $4 a$ and $4 b$, given hydrolysed niacytin, and that in group 2, given free nicotinic acid, were similar, namely 5,3 and $3 \%$ respectively (see Table 1). The excretion of trigonelline in these groups returned to the pre-dose value after, at the most, 3 days. It can be seen that the excretion of trigonelline after a dose of niacytin was well above that of the control groups over the entire experimental period, except on the first day after dosing.

The conversion of the nicotinic acid moiety of niacytin into trigonelline (group 3) was calculated to be $27 \%$. Since there was great variation of trigonelline excretion values before dosing, it was considered appropriate to estimate this recovery by comparison of the trigonelline excretion in the niacytin-dosed group (group 3) with values derived from the average of the pre-dose excretion of group 3 and from the average excretion of groups 1, 2 and $4 a$ on days 10 and 13. The losses during urine collection and extraction have not been corrected for in this value, and the actual conversion is probably about $30-40 \%$. The maximum trigonelline excretion was found after 3 days, in agreement with the findings in the preliminary experiments, and the excretion had not completely returned to a value comparable with that of the undosed control group 14 days after the single dose (Fig. 2).

Excretion of Ehrlich-positive substances in urine. The excretion of Ehrlich-positive substances, assayed in fraction 1 from the ion-exchange procedure, is calculated by comparison with the Ehrlich reaction of niacytin, assuming that nicotinic acid and the Ehrlich-positive substance are present in equimolar quantities, as suggested by Kodicek \& Wilson (1960). Thus the results are expressed in terms of ' $\mu \mathrm{mol}$ of Ehrlich-positive substances'. The excretion of Ehrlich-positive substances was somewhat elevated after the niacytin dose. This approximately paralleled the trigonelline excretion in the niacytin-dosed group 3 (see Fig. 3).

Identification of the niacytin metabolite. (i) Further fractionation on t.l.c. and chemical determination. Urine samples ( 10 or $20 \mathrm{ml}$ ) from the undosed control
Table 1. Estimated recoveries of single doses of nicotinic acid, niacytin and hydrolysed niacytin as trigon. elline, each dose containing $1 \mathrm{mg}$ of nicotinic acid, during 14 days after the dose

\begin{tabular}{clc} 
Group & \multicolumn{1}{c}{ Dose } & Recovery (\%) \\
2 & Nicotinic acid & 3 \\
3 & Niacytin & 27 \\
$4 a$ & Hydrolysed niacytin & 5 \\
$4 b$ & Hydrolysed niacytin & 3 \\
\hline
\end{tabular}

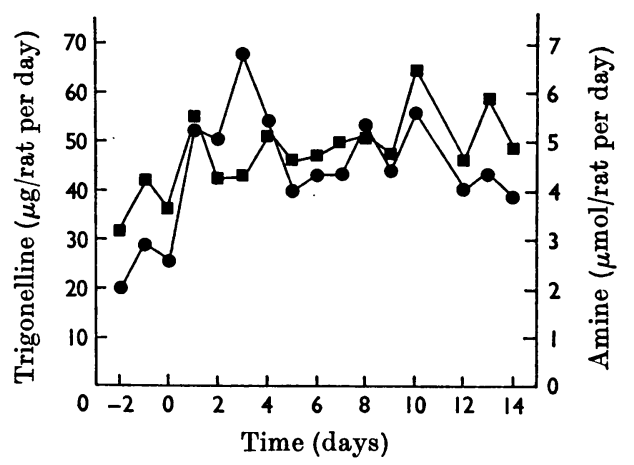

Fig. 3. Excretion of trigonelline (๑) compared with excretion of Ehrlich-positive substances (amine) (a) in urine of rats dosed with niacytin containing $1 \mathrm{mg}$ of nicotinic acid on day 0 . The excretion of Ehrlich-positive substances was determined in a fraction of urine after ion-exchange chromatography on Dowex 50W $\left(\mathrm{Na}^{+}\right.$form and $\mathrm{H}^{+}$form) by reaction with Ehrlich's reagent, and compared with the reaction of niacytin with Ehrlich's reagent as described in the text.

group were fractionated by ion-exchange chromatography as described above. Samples equivalent to $5 \mathrm{ml}$ of urine were applied to silica-gel thin layers as $3 \mathrm{~cm}$ bands and the chromatograms were developed in system I or II. Fractions corresponding to the u.v.-absorbing substances (at $254 \mathrm{~nm}$ ) on the plate were scraped off, eluted and assayed chemically for trigonelline. Substances reacting similarly to trigonelline are referred to as 'benzidine-positive substances'. In system I small amounts of benzidinepositive material were found chromatographing at $R_{F} 0.6-0.9$ and $90 \%$ of the benzidine-positive substances co-chromatographed with authentic trigonelline at $R_{F} 0.21$ (fraction A). The results of a typical experiment are shown in Table 2. The amount of benzidine-positive substances at high $R_{F}$ (fraction $\mathrm{B}$ ) was shown not to be dose-dependent. The amount of trigonelline found was closely comparable with the results obtained from samples fractionated only by ion-exchange chromatography. In system II again over $90 \%$ of the benzidine-positive substances 
Table 2. Fractionation by t.l.c. of substances of urine, after purification by ion-exchange chromatography, that react as trigonelline in the chemical determination (see the text)

\begin{abstract}
Samples of urine from rats dosed with niacytin and from undosed controls were fractionated on Dowex and portions chromatographed by t.l.c. in system I. Two fractions were eluted and assayed colorimetrically for trigonelline. Fraction A corresponds to authentic trigonelline, at $R_{F} 0.21$, fraction $B$ to the remaining substances on the t.l.c. plate. Values in the final column refer to the recovery of trigonelline in fraction A compared with the amount determined in the extract before t.l.c.
\end{abstract}

\begin{tabular}{|c|c|c|c|c|c|c|}
\hline \multirow[b]{2}{*}{ Group } & \multirow[b]{2}{*}{ Dose } & \multirow{2}{*}{$\begin{array}{c}\text { Time } \\
\text { after dose } \\
\text { (days) }\end{array}$} & \multicolumn{2}{|c|}{$\begin{array}{c}\text { 'Trigonelline' in fractions } A \text { and } B \\
(\mu \mathrm{g} / \text { rat per day })\end{array}$} & \multirow{2}{*}{$\begin{array}{l}\% \text { in } \\
\text { fraction B }\end{array}$} & \multirow{2}{*}{$\begin{array}{l}\text { Recovery } \\
\quad(\%)\end{array}$} \\
\hline & & & Fraction A & Fraction B & & \\
\hline 1 & Undosed & 8 & 23 & 2.2 & 9 & 115 \\
\hline 3 & Niacytin & 8 & 53 & 0.2 & 0.3 & 100 \\
\hline 1 & Undosed & 13 & 25 & 2.2 & 9 & 91 \\
\hline 3 & Niacytin & 13 & 40 & 3.1 & 8 & 100 \\
\hline
\end{tabular}

co-chromatographed with authentic trigonelline at $R_{F} 0.51$, the remaining approx. $10 \%$ being distributed along the chromatogram. In a further experiment the trigonelline band from a chromatogram developed in system II was eluted and rechromatographed in system I. It was found that over $80 \%$ of the total benzidine-positive material co-chromatographed with authentic trigonelline in both systems.

(ii) Co-chromatography with authentic trigonelline on t.l.c. Portions of the trigonelline fraction prepared from urine from undosed rats (groups 1) and niacytin-dosed rats (group 3) by ion-exchange chromatography, as described above, were subjected to t.l.c. in systems $I$ and II. In both systems a band corresponding to authentic trigonelline was found, of greater intensity from the urine of the dosed than from the undosed animals, at $R_{F} 0.21$ in system I and $R_{F} \mathbf{0 . 5 1}$ in system II. This band co-chromatographed exactly with authentic trigonelline added before chromatography. Further samples chromatographed preparatively in system II and rechromatographed in system I showed trigonelline as the only spot in the second chromatogram, again with a greater amount present in urine from niacytin-dosed rats than from undosed rats.

(iii) U.v. spectroscopy. A sample of the niacytin metabolite purified by ion-exchange chromatography, then by preparative t.l.c. in system II followed by system I, had a u.v. spectrum identical with that of authentic trigonelline, with $\lambda_{\max }$. at $265 \mathrm{~nm}$ and a shoulder at $270 \mathrm{~nm}$.

(iv) G.l.c. of trigonelline as methyl nicotinate. In a number of experiments urine was fractionated by ion-exchange chromatography, the trigonelline fraction was divided into two and authentic trigonelline was added to one half, and the samples were further purified by preparative t.l.c. in system II. This t.l.c. system separated trigonelline from known nicotinoyl-containing substances $\left(R_{F}\right.$ values found were: trigonelline, 0.51 ; nicotinic acid, 0.83 ; nicotinamide, $0.78 ; N^{\prime}$-methylnicotinamide, 0.03 ; methyl nicotinate, $0.88 ; N^{\prime}$-methylpyrid-2-one-5carboxamide, 0.85 ; NMN, $0-0.1$; NAD, 0-0.2; niacytin, 0.00). The trigonelline fraction was then treated for conversion of trigonelline into methyl nicotinate as described above, and $5 \mu$ portions of the final 0.1 ml of aqueous solutions were subjected to g.l.c. in two different systems. Peaks corresponding ta authentic methyl nicotinate were found in both g.l.o. systems, increased in area for the samples containing internal standards. Although the reqults were non-quantitative owing to losses and variable yields a greater amount of methyl nicotinate was found from urine from niacytindosed animals than from the undosed controls. The g.l.c, nystems separated methyl nicotinate from the products formed from some analogues after treatment by the procedure used for conversion of trigonelline into methyl nicotinate (Table 3). Other analogues, e.g. nicotinic acid and $N^{\prime}$-methylnicotinamide, were separated by t.l.c. as described above. These experiments provided further evidence that the metabolite previously identified as trigonelline contained the nicotinoyl moiety.

\section{DISCUSSION}

Niacytin has been shown not to be metabolized via free nicotinic acid, nor to be excreted unchanged in the faeces (Mason \& Kodicek, 1970). Further, in the present investigations it was shown that niacytin was not excreted as $N^{\prime}$-methylated derivatives in faeces. Evidence was thus provided that the nicotinic acid-containing part of the molecule was not excreted in the faeces and hence was absorbed. Further, a metabolite was detected in urine and determined chemically to be trigonelline. Its identity was further established by t.l.c., u.v. spectroscopy and g.l.c. (this last strictly identified 
Table 3. Retention times of some nicotinic acid analogues on g.l.c., chromatographed after the procedure for conversion of trigonelline into methyl nicotinate (see the text)

The column conditions are as described in the text. The retention time of authentic methyl nicotinate was 2.7min (Apiezon L) and $27 \mathrm{~min}$ (Carbowax 400).

\begin{tabular}{lcc}
\multicolumn{1}{c}{ Compound } & \multicolumn{2}{c}{ Retention time of product (min) } \\
\cline { 2 - 3 } Nicotinic acid & $10 \%$ Apiezon L, $150^{\circ} \mathrm{C}$ & $4 \%$ Carbowax $400,100^{\circ} \mathrm{C}$ \\
Trigonelline & 2.7 & 27 \\
Isonicotinic acid & 2.7 & 27 \\
Picolinic acid & 2.3 & 22 \\
$N^{\prime}$-Methylnicotinamide & $*$ & 27 \\
$N^{\prime}$-Methylpyrid-2-one-5-carboxamide & 2.7 & $*$ \\
6-Methylnicotinic acid & 4.0 & 34 \\
6-Hydroxynicotinic acid & 4.2 & $*$ \\
& $*$ &
\end{tabular}

the nicotinoyl moiety). In the control groups, dosed with free nicotinic acid and with hydrolysed niacytin, a small conversion (approx. 3-5\%) of nicotinic acid into trigonelline appeared to occur. This conflicts with the generally held view that nicotinic acid itself is not converted into trigonelline in the rat (Hundley, 1954), although Ackermann (1913) reported the isolation of trigonelline from the urine of dogs given high doses of nicotinic acid $19 \mathrm{~g}$ in 5 days). In studies with labelled nicotinic acid labelled trigonelline was not found in urine, although it was possibly not investigated as such (e.g. Petrack, Greengard \& Kalinsky, 1966).

The trigonelline excretion in the niacytin-dosed groups had nearly returned to the value of the undosed control animals after 14 days. Since only $30-40 \%$ of the nicotinic acid in the niacytin dose was recovered as trigonelline, this implies that other metabolites were present. An increase in the excretion of other substances was found by t.l.c.; these substances were not investigated further, except to note that none appeared to be $N^{\prime}$-methylnicotinuric acid or to be a 'bound' form of trigonelline. It is possible that trigonelline was metabolized further, for example similarly to $N^{\prime}$-methylnicotinamide to form pyridones. It is of note that Huff \& Perlzweig (1943) found that only $20-40 \%$ of an oral dose of $1.5 \mathrm{mg}$ of trigonelline was recovered unchanged in urine within $24 \mathrm{~h}$ in the rat; Handler \& Dann (1942) found that inclusion of approx. $80 \mathrm{mg}$ of trigonelline/day in the diet of rats gave a recovery of $50-80 \%$ of trigonelline unchanged in the urine. Moreover, McKennis, Bowman, Horvath \& Bederka (1964) showed that 92-97\% of the radioactivity from $\left[M e-{ }^{14} \mathrm{C}\right]$ trigonelline was recovered in the urine within $24 \mathrm{~h}$. It has also been shown that trigonelline is not converted into $N^{\prime}$-methylnicotinamide in vivo and is thus not a source of nicotinic acid (Ellinger, Fraenkel \& Abdel Kader, 1947).
The finding that trigonelline is a major metabolite of niacytin in the urine suggests a pathway for its metabolism in the rat. Since niacytin itself has been reported to have a molecular weight of approx. 2500 (Kodicek \& Wilson, 1960), it is postulated that a fragment of a lower molecular weight is formed by hydrolysis in the gastrointestinal tract and is then absorbed. That absorption of parts of the niacytin molecule occurs is shown, not only by the trigonelline excretion, but also by the increased excretion of Ehrlich-positive substances, and by the failure to find the nicotinoyl moiety in faeces. Since less than $1 \%$ of the nicotinic acid in the niacytin dose is found as tertiary nicotinoyl derivatives in faeces, this postulated fragment is clearly not excreted unchanged.

Since niacytin is not available to the rat and is not metabolized via free nicotinic acid, $N$-methylation of the nicotinoyl moiety clearly occurs before liberation of the nicotinic acid. The only enzyme known that might bring about this methylation is nicotinamide methyltransferase (EC 2.1.1.1) (Cantoni, 1951). The specificity of this enzyme is not fully known, and thus whether it would be active on the nicotinoyl moiety in the molecule of niacytin is unknown. Equally, whether the hydrolysis of the $N$-methylated fragment is spontaneous or brought about by the action of an enzyme is unknown, although clearly the structure of the niacytin molecule or its fragment must be sufficiently changed by the methylation to allow hydrolysis of the methylated nicotinic acid to occur. The extremely slow metabolism of niacytin might be due to the absence of any specific enzyme system or to an impairment of metabolic functions in the nicotinic acid-deficient animal. The excretion of the Ehrlich-positive substances in urine, which was found to parallel approximately the trigonelline excretion, indicates that the Ehrlich-positive 
substance derived from niacytin is released with the trigonelline.

This scheme would partially account for the fate of niacytin. Its unavailability appears to be due to the inability of the animal to hydrolyse the molecule to free nicotinic acid, the nicotinic acid moiety being excreted as trigonelline without passing through a free nicotinic acid stage. Hitherto, no endogenous source of trigonelline was known; it is now clear that the presence of trigonelline in urine is also partly due to metabolism of dietary niacytin.

\section{REFERENCES}

Ackermann, D. (1913). Z. Biol. 59, 17.

Cantoni, G. L. (1951). J. biol. Chem. 189, 203.

De Boer, T. J. \& Backer, H. F. (1954). Recl Trav. chim. Pays-Bas Belg. 73, 229.

Ellinger, P., Fraenkel, G. \& Abdel Kader, M. M. (1947). Biochem. J. 41, 559.
Eneroth, P. \& Lindstedt, G. (1965). Analyt. Biochem. 10, 479.

Handler, P. \& Dann, W. J. (1942). J. biol. Chem. 146, 357. Huff, J. W. \& Perlzweig, W. A. (1943). J. biol. Chem. 150, 395.

Hundley, J. M. (1954). In The Vitamins, vol. 4, p. 314. Ed. by Sebrell, W. H. \& Harris, R. S. London: Academic Press (Inc.) Ltd.

Joshi, J. G. \& Handler, P. (1962). J. biol. Chem. 237, 3185. Kodicek, E. \& Wang, Y. L. (1941). Nature, Lond., 148, 23.

Kodicek, E. \& Wilson, P. W. (1960). Biochem. J. 76, 27 P. McKennis, H., Bowman, E. R., Horvath, A. \& Bederka, J. P. (1964). Nature, Lond., 202, 699.

Mason, J. B. \& Kodicek, E. (1968a). Biochem. J. 107, 23 P. Mason, J. B. \& Kodicek, E. (1968b). Abstr. FE BS 5th Meet., Prague, p. 75.

Mason, J. B. \& Kodicek, E. (1970). Biochem.J.120, 509.

Petrack, B., Greengard, P. \& Kalinsky, H. (1966). J. biol. Chem. 241, 2367.

Wall, J. S. (1953). Analyt. Chem. 25, 950. 